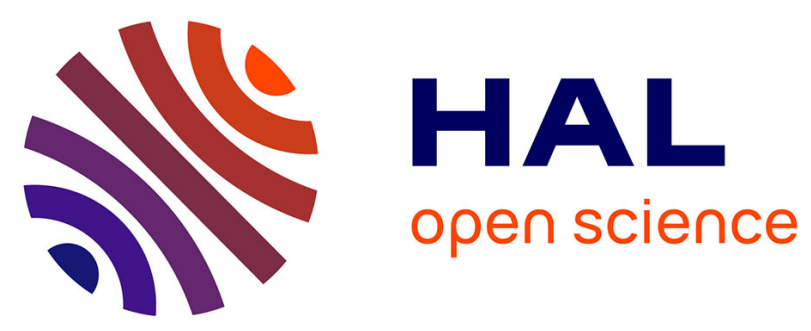

\title{
Superparamagnetic iron oxide nanoparticles (SPIONs)-loaded Trojan microparticles for targeted aerosol delivery to the lung
}

Frederic Tewes, Carsten Ehrhardt, Anne Marie Healy

\section{- To cite this version:}

Frederic Tewes, Carsten Ehrhardt, Anne Marie Healy. Superparamagnetic iron oxide nanoparticles (SPIONs)-loaded Trojan microparticles for targeted aerosol delivery to the lung. European Journal of Pharmaceutics and Biopharmaceutics, 2014, 86, pp.98 - 104. 10.1016/j.ejpb.2013.09.004 . inserm01102561

\section{HAL Id: inserm-01102561 https://www.hal.inserm.fr/inserm-01102561}

Submitted on 13 Jan 2015

HAL is a multi-disciplinary open access archive for the deposit and dissemination of scientific research documents, whether they are published or not. The documents may come from teaching and research institutions in France or abroad, or from public or private research centers.
L'archive ouverte pluridisciplinaire HAL, est destinée au dépôt et à la diffusion de documents scientifiques de niveau recherche, publiés ou non, émanant des établissements d'enseignement et de recherche français ou étrangers, des laboratoires publics ou privés. 
1 Superparamagnetic iron oxide nanoparticles (SPIONs)-loaded

2 Trojan microparticles for targeted aerosol delivery to the lung

3 Frederic Tewes ${ }^{1,2}$, Carsten Ehrhardt ${ }^{1}$ and Anne Marie Healy ${ }^{1 *}$

4 1- School of Pharmacy and Pharmaceutical Sciences, Trinity College Dublin, Panoz

5 Institute, College Green, Dublin 2, Ireland.

6

7 2- INSERM U 1070, Pôle Biologie-Santé, Faculté de Médecine \& Pharmacie,

8 Université de Poitiers, 40 av. du Recteur Pineau, 86022 Poitiers Cedex, France

9

$10 *$ To whom correspondence should be sent. Ph.: 003531896 1444, e-mail:

11 healyam@tcd.ie

12 


\section{Abstract}

14 Targeted aerosol delivery to specific regions of the lung may improve therapeutic

15 efficiency and minimise unwanted side effects. It could potentially be achieved with

16 porous microparticles loaded with superparamagnetic iron oxide nanoparticles (SPIONs)

17 - in combination with a target-directed magnetic gradient field. As a proof of concept of

18 this hypothesis, the aim of this study was to formulate and evaluate the aerodynamic

19 properties of SPIONs-loaded Trojan microparticles after delivery from a dry powder

20 inhaler. Microparticles made of SPIONs, PEG and hydroxypropyl- $\beta$-cyclodextrin

21 (HP $\beta C D)$ were formulated by spray drying and characterised by various physicochemical

22 methods. Aerodynamic properties were evaluated using a next generation cascade

23 impactor (NGI), with or without a magnet positioned at stage 2. Mixing appropriate

24 proportions of SPIONs, PEG and HP $\beta C D$ allowed Trojan microparticle to be formulated.

25 These particles had a median geometric diameter of $2.8 \pm 0.3 \mu \mathrm{m}$ and were shown to be

26 sensitive to the magnetic field induced by a magnet having a maximum energy product of

$27413.8 \mathrm{~kJ} / \mathrm{m}^{3}$. However, these particles, characterised by a mass median aerodynamic

28 diameter $(\mathrm{MMAD})$ of $10.2 \pm 2.0 \mu \mathrm{m}$, were considered to be not inhalable. The poor

29 aerodynamic properties resulted from aggregation of the particles. The addition of

$30\left(\mathrm{NH}_{4}\right)_{2} \mathrm{CO}_{3}$ and magnesium stearate $(\mathrm{MgST})$ to the formulation improved the

31 aerodynamic properties of the Trojan particles, and resulted in a MMAD of $2.2 \pm 0.8 \mu \mathrm{m}$.

32 In the presence of a magnetic field on stage 2 of the NGI, the amount of particles

33 deposited at this stage increased 4 -fold from $4.8 \pm 0.7 \%$ to $19.5 \pm 3.3 \%$. These Trojan

34 particles appeared highly sensitive to the magnetic field and their deposition on most of

35 the stages of the NGI was changed in the presence compared to the absence of the 
36 magnet. If loaded with a pharmaceutical active ingredient, these particles may be useful

37 for treating localised lung disease such as cancer nodules or bacterial infectious foci. 


\section{Introduction}

40 Pharmacotherapy of lung diseases often involves direct delivery of active pharmaceutical

41 ingredients (APIs) by pulmonary inhalation. However, despite the progress in aerosol

42 delivery to the lung, administration systems are still unable to effectively deliver the dose

43 to the optimal areas of deposition within the respiratory tract. Optimising the deposition

44 pattern of API within the most suitable part of the airways should increase the efficacy of

45 the treatment and reduce side effects. This should be beneficial for treating localised lung

46 diseases, such as respiratory infection and lung cancer, i.e. by targeting foci of bacterial

47 infection or tumour nodules.

48 Superparamagnetic iron oxide nanoparticles (SPIONs), such as nanoparticles of

49 maghemite $\left(\gamma-\mathrm{Fe}_{2} \mathrm{O}_{3}\right)$ or magnetite $\left(\mathrm{Fe}_{3} \mathrm{O}_{4}\right)$ offer attractive magnetic properties. However,

50 SPIONs dispersions are unstable at physiological $\mathrm{pH}$ and surface modifications are

51 required to increase their stability in aqueous media. SPION coated dispersions are one of

52 the few FDA approved nanoparticles for use as MRI contrast agents [1]. Lately, SPIONs

53 were also envisaged as sensitive devices for magnetic drug targeting after intravenous

54 nanoparticles administration, in combination with a target-directed magnetic gradient

55 field [2-6].

56 This concept has also been applied in an attempt to target dry nanoparticle aerosols

57 within the lung using magnetically driven deposition [7, 8]. However, it has been

58 demonstrated that, even with optimised magnet design, the resulting magnetic forces

59 would not be sufficient to efficiently guide individual SPIONs in a dry-powder aerosol

60 because of their small magnetic moment [9]. In contrast, when a multitude of SPIONs are

61 assembled in an liquid aerosol droplet as a nanomagnetosol, the magnetic moment of the 
62 assembly increased, which resulted in aerosols which were guidable by medically

63 compatible magnetic fields [9]. Also, recently, inert SPIONs added to the nebuliser

64 solution were used to guide the aerosol to the affected region of the lung by means of a

65 strong external magnetic field. Various therapeutic agents have been administrated by

66 this technique [10].

67 However, the small size of nanoparticles can lead to particle-particle aggregation, 68 making their physical handling difficult in liquid and dry powder forms [11]. The

69 delivery of API to the lung may be achieved by using dry powder inhalers (DPIs),

70 metered dose inhalers or nebulisers. In the solid form, as in a DPI, pharmaceutical

71 ingredients are usual more stable than in liquid form. Therefore, with the same concept of

72 increasing the magnetic moment, targeted aerosol delivery to a specific area of the lung

73 could also be achieved with Trojan microparticles loaded with SPIONs. Trojan particles

74 are microparticles composed of nanoparticles and additional components used to

75 maintain the nanoparticles together. Once in the body, the microparticles disaggregate

76 and release the nanoparticles. Trojan particles were previously formulated and reported as

77 being an efficient means of administering nanoparticles to the lung by inhalation [11].

78 These nano-in-microparticle systems should allow for higher aerosolisation and delivery

79 efficiency than nanoparticles and permit the focalization of the drug reservoir in the

80 targeted area.

81 To reach the deep lung alveolar region, particles require a 1-5 $\mu \mathrm{m}$ aerodynamic diameter

82 range. This aerodynamic diameter range corresponds to spherical particles of unit density

83 having a 1 - $5 \mu \mathrm{m}$ geometric diameter range. Iron oxide density is $4.9 \mathrm{~g} / \mathrm{cm}^{3}$ and 5.2

$84 \mathrm{~g} / \mathrm{cm}^{3}$ for maghemite and magnetite, respectively. Therefore, the best way to nebulise 
85 microparticles composed of iron oxide is to develop porous hybrid particles with a 86 reduced density. In fact, to optimise the efficacy of dry powder inhalation, porous 87 particles with low apparent density were developed [12]. For instance, tobramycin 88 powder was produced using the emulsion-based PulmoSphere technology, producing 89 highly dispersible porous particles [13]. Excipient-free nanoporous microparticles 90 (NPMPs) [14-17] prepared by a spray drying process had improved in vitro deposition 91 properties compare to non-porous microparticles. Trojan large porous particle composed 92 of polymeric nanoparticles were also formulated by spray drying and exhibited much 93 better flow and aerosolisation properties than the nanoparticles from which they were 94 prepared [11]. Therefore, the aim of this study was to formulate SPIONs-loaded Trojan 95 porous microparticles for aerosol lung magnetic targeting after administration using a dry 96 powder inhaler. 


\subsection{Materials}

101 Hydroxypropyl- $\beta$-cyclodextrin (HP $\beta C D$ ) with an average degree of substitution of 0.65

102 (Encapsin ${ }^{\mathrm{TM}}$ HPB) was purchased from Janssen Biotech, Olen, Belgium. Linear PEG

103 10kDa (PEG), alkanes with 99.8\% purity (hexane, heptane, octane, nonane, decane and

104 undecane), maghemite $\left(\mathrm{Fe}_{2} \mathrm{O}_{3}\right)$ nanoparticles (SPIONs) with a mean diameter of $50 \mathrm{~nm}$,

105 magnesium stearate $(\mathrm{MgST})$ and ammonium carbonate $\left(\left(\mathrm{NH}_{4}\right)_{2} \mathrm{CO}_{3}\right)$ were all purchased

106 from Sigma-Aldrich, (Dublin, Ireland).

\subsection{Methods}

\subsubsection{Spray drying}

109 Various suspensions containing SPIONs were spray dried using a B-290 Mini spray dryer

110 (Büchi, Flawil, Switzerland) set in the closed cycle mode with a 2-fluid nozzle. The

111 liquid phase of the suspensions was composed of butyl acetate/methanol/water mixture

112 with a volume ratio 5:5:1, as used previously [18]. The composition of the suspensions is

113 described in Table 1. The spray dryer was operated as follows: Inlet temperature was

$11465^{\circ} \mathrm{C}$; feeding pump was set at $30 \%$; spraying $\mathrm{N}_{2}$ nozzle flow rate was $15 \mathrm{~L} / \mathrm{min} ; \mathrm{N}_{2}$

115 flowing at $670 \mathrm{NL} / \mathrm{h}$ was used as the drying gas. These conditions resulted in an outlet 116 temperature ranging from 36 to $39^{\circ} \mathrm{C}$. 
118 Table 1: Concentration $(\mathrm{g} / \mathrm{L})$ of materials in the spray dried solutions and formulation code.

\begin{tabular}{|c|c|c|c|c|c|c|c|c|c|}
\hline & $\begin{array}{c}25 \mathrm{P}- \\
75 \mathrm{H}- \\
5 \mathrm{~F}\end{array}$ & $\begin{array}{c}25 \mathrm{P}- \\
75 \mathrm{H}- \\
30 \mathrm{~F}\end{array}$ & $\begin{array}{c}50 \mathrm{P}- \\
50 \mathrm{H}- \\
50 \mathrm{~F}\end{array}$ & $\begin{array}{c}50 \mathrm{P}- \\
50 \mathrm{H}- \\
50 \mathrm{~F}- \\
\mathrm{CO}_{3}\end{array}$ & $\begin{array}{c}100 \mathrm{P}- \\
50 \mathrm{~F}\end{array}$ & $\begin{array}{c}100 \mathrm{P}- \\
50 \mathrm{~F}- \\
\mathrm{CO}_{3}\end{array}$ & $\begin{array}{c}100 \mathrm{H}- \\
50 \mathrm{~F}\end{array}$ & $\begin{array}{c}50 \mathrm{P}- \\
50 \mathrm{H}- \\
50 \mathrm{~F}-\mathrm{ST}\end{array}$ & $\begin{array}{c}50 \mathrm{P}- \\
50 \mathrm{H}- \\
50 \mathrm{~F}- \\
\mathrm{CO}_{3} \text {-ST }\end{array}$ \\
\hline $\mathrm{Fe}_{2} \mathrm{O}_{3}$ & 5 & 30 & 50 & 50 & 50 & 50 & 50 & 50 & 50 \\
\hline $\mathrm{PEG}$ & 25 & 25 & 50 & 50 & 100 & 100 & 0 & 50 & 50 \\
\hline $\mathrm{HP} \beta \mathrm{CD}$ & 75 & 75 & 50 & 50 & 0 & 0 & 100 & 50 & 50 \\
\hline$\left(\mathrm{NH}_{4}\right)_{2} \mathrm{CO}_{3}$ & 0 & 0 & 0 & 25 & 0 & 25 & 0 & 0 & 25 \\
\hline $\mathrm{MgST}$ & 0 & 0 & 0 & 0 & 0 & 0 & 0 & 6 & 6 \\
\hline
\end{tabular}

\subsubsection{Scanning electron microscopy (SEM)}

121 SEM micrographs of samples were taken using a Tescan Mira XMU (Tescan s.r.o.,

122 Czech Republic) electron microscope. The samples were fixed on aluminium stubs and

123 coated with a $10 \mathrm{~nm}$-thick gold film. Primary electrons were accelerated under a voltage

124 of $5 \mathrm{kV}$. Images were formed from the collection of secondary electrons.

\subsubsection{Powder X-ray diffraction (XRD)}

126 XRD measurements were conducted on samples placed in a low background silicon

127 holder, using a Rigaku Miniflex II desktop X-ray diffractometer (Rigaku, Tokyo, Japan).

128 The samples were scanned over a range of $5-40^{\circ} 2 \theta$ at a step size of $0.05^{\circ}$ s as 129 previously described [19].

$130 \quad$ 2.2.4 Particle size distribution analysis

131 The geometric particle size distributions (PSD) were determined by laser diffraction

132 using a Mastersizer 2000 (Malvern Instruments, Worcestershire, UK) with the Scirocco

1332000 dry powder feeder to disperse the particles as described previously [19]. The

134 dispersive air pressure used was 3 bar and vibration feed rate was set to $50 \%$. Data were 135 analysed based on the equivalent volume median diameter, $D_{50}$, and the span of the PSD.

136 Calculation was performed using Mie theory and refractive index part of 2 and absorption 
137 part of 1 as optical particle properties $(n=2)$.

\section{$138 \quad$ 2.2.5 Particle true density}

139 The true density of the materials was measured using an Accupyc 1330 Pycnometer

140 (Micromeritics $\left.{ }^{\circledR}\right)$ with helium (99.995\% purity) to determine the volume of accurately

141 weighed samples. Samples were dried prior to measurement for $24 \mathrm{~h}$ in a Gallenkamp

142 vacuum oven operating at $600 \mathrm{mbar}$ and $25^{\circ} \mathrm{C}(\mathrm{n}=2)$.

\subsubsection{Surface free energy measurement}

144 Measurements were performed at $0 \% \mathrm{RH}$ or $40 \% \mathrm{RH}$ and $30^{\circ} \mathrm{C},(\mathrm{n}=3)$ using an inverse 145 gas chromatography (iGC) instrument (SMS Ltd., London, UK). Powders were packed 146 into a silanized glass column $(300 \mathrm{~mm} \times 3 \mathrm{~mm})$, and then pre-treated for $1 \mathrm{~h}$ at $30^{\circ} \mathrm{C}$ and

$1470 \% \mathrm{RH}$. Then, $250 \mu \mathrm{L}$ of the probe vapour-helium mixture was injected into the helium

148 flow. All injections of probe vapours were performed at $0.03 \% \mathrm{v} / \mathrm{v}$ of the saturated probe

149 vapour. A flame ionization detector was used to monitor the probes' elution. In acid-base

150 theory, the total surface free energy of a solid $\left(\gamma_{s}^{T}\right)$ has 2 main components: a dispersive

151 contribution $\left(\gamma_{s}{ }^{d}\right)$ and specific or acid-base contribution $\left(\gamma_{s}^{A B}\right)$ which are independent and

152 additive. In order to calculate $\gamma_{s}{ }^{d}$ of the particles, alkane probes with a known dispersive

153 contribution $\left(\gamma_{p}{ }^{d}\right)$ and a nil specific contribution $\left(\gamma_{p}{ }^{A B}\right)$ were used. Methane was used as

154 inert reference. At this low $\%$ of saturation $(0.03 \% \mathrm{v} / \mathrm{v})$, iGC was used in infinite dilution

155 conditions and $\gamma_{s}{ }^{d}$ was calculated using the method developed by Schultz et al. [20].

\section{$156 \quad$ 2.2.7 Aerodynamic particle diameter analysis}

157 The aerodynamic diameter (AD) distribution of the particles was measured using a Next

158 Generation Impactor (NGI) as previously described [19]. The flow rate was adjusted to 159 get a pressure drop of $4 \mathrm{kPa}$ in the powder inhaler (Handihaler ${ }^{\circledR}$, Boeringher Ingelheim, 160 Ingelheim, Germany) and the time of aspiration was adjusted to obtain $4 \mathrm{~L}$. The inhaler 
161 was filled with gelatin $n^{0} 3$ capsule loaded with $20 \pm 2 \mathrm{mg}$ of powder $(\mathrm{n}=3)$. After inhaler

162 actuation, particle deposition on the NGI was determined by the SPIONs assay as

163 described below. The amount of particles recovered on each stage expressed as a

164 percentage of the emitted recovered dose was considered as the fine particle fraction

165 (FPF). The mass median aerodynamic diameter (MMAD) and FPF were calculated as

166 previously described [19]. Additional experiments were performed in the presence of a

167 neodymium iron boron magnet (e-Magnets UK, Hertfordshire UK) of $20 \mathrm{~mm}$ of diameter

168 and $20 \mathrm{~mm}$ of length having a maximum energy product $\left(\mathrm{BH}_{\max }\right)$ of $413.8 \mathrm{~kJ} / \mathrm{m}^{3}$ placed

169 on the bottom of the stage 2 of the NGI.

$170 \quad$ 2.2.8 SPIONs concentration assay

171 SPIONs assay was performed by turbidity measurements at $510 \mathrm{~nm}$. SPIONs were

172 dispersed in $2 \% \mathrm{w} / \mathrm{w}$ poly (vinyl alcohol) $(10 \mathrm{kDa})$ solution containing $0.1 \mathrm{M}$ of $\mathrm{NaOH}$

173 using a sonicator bath. In the case of formulations containing MgST, particles were

174 dispersed in a $1 / 1(\mathrm{v} / \mathrm{v})$ mixture of ethanol and an aqueous solution composed of $2 \% \mathrm{w} / \mathrm{w}$

175 PVA (10kDa) and $0.1 \mathrm{M}$ of $\mathrm{NaOH}$. In these conditions, stable suspensions were obtained.

176 Calibration curves were constructed with standard suspensions composed of SPIONs

177 dispersed in the same media as the formulations and having concentrations ranging from

$178 \quad 0.001$ to $0.05 \mathrm{mg} / \mathrm{mL}$.

$179 \quad$ 2.2.9 Statistical data analysis

180 Data were statistically evaluated by a two-way ANOVA using Excel ${ }^{\circledR}$ software 181 (Microsoft). Significance level was $\alpha<0.05$. 


\section{2- Results and discussion}

184 Powder XRD patterns recorded for the powders made of PEG, HP $\beta C D$ and SPIONs

185 (Fig. 1) had curved baselines and diffraction peaks at 30.3 and $35.62 \theta$ degrees

186 corresponding to maghemite iron oxide [21]. The intensity of the diffraction peaks

187 increased with an increasing amount of SPIONs incorporated in the formulation. PEG

188 residual crystallinity was also observed in formulations containing more than $33 \mathrm{wt} \%$ of

189 PEG from the presence of the two major diffraction peaks at 19.2 and $23.32 \theta$ degrees

$190[18,19]$. The absence of diffraction peaks corresponding to the HP $\beta C D$, suggested that

191 this excipient was in the XRD amorphous state.

192 For spray dried systems comprising PEG, HP $\beta C D$ and SPIONs, SEM pictures showed

193 individual spherical microparticles surrounded by SPIONs nanoparticles (Figure 2A-B-

194 D). This morphology was obtained due to the high Peclet number of the SPIONs relative

195 to the other excipients, resulting in accumulation on the surface of the microparticles [11,

196 22]. Without PEG in the formulation, heterogeneous blends of free SPIONs and HP $\beta C D$

197 microparticles were obtained (data not shown). This failure to form the Trojan

198 microparticles may be as a result of the van der Waals forces between the SPIONs

199 accumulated on the microparticles being too low to enable them be retained on the

200 surface [11] and could also be due to the weak adhesion between HP $\beta C D$ and SPIONs.

201 Volume weighted particle size distributions of these particles (100H-50F) showed a large

202 proportion of nanoparticles (Fig. 3F). In the absence of HP $\beta C D$, large particle aggregates

203 were produced and the presence of SPIONs was not visible (Figure 2C). These

204 aggregates were thought to result from the low and broad melting temperature of the

205 PEG, leading to the formation in the spray dryer of partly solidified sticky particles [18, 
19]. The absence of visible SPIONs suggests that these soft particles embed SPIONs in

207 their bulk, before complete solidification. These particles (100P-50F) had the highest

208 geometric median diameter, as measured by laser diffraction, compared to the other

209 formulations containing PEG and HP $\beta$ CD (Fig. 3 - curve A), resulting also in the lowest

210 specific surface area (Table 2). Due to their large size, these particles were considered to

211 be not suitable for pulmonary administration. These particles presented the lowest

212 dispersive surface free energy $\left(\gamma_{s}^{d}\right)$ values $\left(36 \pm 1 \mathrm{~mJ} / \mathrm{m}^{2}\right)$, similar to values found

213 previously for PEG alone $\left(37.7 \pm 4 \mathrm{~mJ} / \mathrm{m}^{2}\right)$ [18], confirming that their surfaces were

214 mainly composed of PEG molecules.

215 Table 2: Physicochemical properties of the Trojan particles. * Data from supplier.

\begin{tabular}{|c|c|c|c|c|c|c|c|c|}
\hline & $25 \mathrm{P}-75 \mathrm{H}-5 \mathrm{~F}$ & \begin{tabular}{|c|}
$25 \mathrm{P}-75 \mathrm{H}-$ \\
$30 \mathrm{~F}$
\end{tabular} & $\begin{array}{c}50 \mathrm{P}-50 \mathrm{H}- \\
50 \mathrm{~F}\end{array}$ & $100 \mathrm{P}-50 \mathrm{~F}$ & $\begin{array}{c}\text { 50P-50H-50F- } \\
\text { CO3 }\end{array}$ & \begin{tabular}{|c}
$50 \mathrm{P}-50 \mathrm{H}-50 \mathrm{~F}-$ \\
ST \\
\end{tabular} & $\begin{array}{c}\text { 50P-50H-50F- } \\
\text { CO3-ST } \\
\end{array}$ & SPION \\
\hline True density $\left(\mathrm{g} / \mathrm{cm}^{3}\right)$ & $1.39 \pm 0.01$ & $1.64 \pm 0.01$ & $1.68 \pm 0.01$ & $1.69 \pm 0.01$ & $1.76 \pm 0.01$ & $1.66 \pm 0.01$ & $1.71 \pm 0.01$ & $2.70 \pm 0.01$ \\
\hline $\begin{array}{c}\text { Specific surface area } \\
\left(\mathrm{m}^{2} / \mathrm{g}\right)\end{array}$ & $4.5 \pm 0.2$ & $4.8 \pm 0.2$ & $3.9 \pm 0.1$ & $1.4 \pm 0.2$ & $3.2 \pm 0.1$ & $6.8 \pm 0.4$ & $4.6 \pm 0.3$ & $46.6 *$ \\
\hline $\begin{array}{l}\text { geometric median } \\
\text { diameter }(\mu \mathrm{m})\end{array}$ & $1.9 \pm 0.2$ & $2.0 \pm 0.4$ & $2.2 \pm 0.4$ & $7.2 \pm 0.7$ & $2.8 \pm 0.3$ & $1.54 \pm 0.2$ & $2.15 \pm 0.3$ & $0.05^{*}$ \\
\hline$\gamma_{s}^{d}\left(\mathrm{~mJ} / \mathrm{m}^{2}\right)$ & $119 \pm 2$ & $149 \pm 27$ & $43 \pm 5$ & $36 \pm 1$ & $39 \pm 2$ & & & \\
\hline $\operatorname{MMAD}(\mu \mathrm{m})$ & & & & & $10.2 \pm 2.0$ & $3.4 \pm 1.1$ & $2.2 \pm 0.8$ & $9.3 \pm 3.1$ \\
\hline GSD & & & & & $2.4 \pm 1.1$ & $2.4 \pm 0.5$ & $2.1 \pm 0.4$ & $4.3 \pm 1.8$ \\
\hline
\end{tabular}

217 The use of PEG allowed SPIONs to stick together to form the Trojan microparticles, but

218 produced large aggregates in the absence of $\mathrm{HP} \beta \mathrm{CD}$. Also, an appropriate ratio between

219 PEG and HP $\beta C D$ was necessary to obtain isolated and spherical Trojan microparticles.

220 Particle deposition on the NGI impactor stages was dependent on the particle type. For

221 SPIONs alone, only $30 \%$ of the nanoparticles emitted out of the gelatin capsule were

222 deposited beyond the first impactor stage, which has a cut-off aerodynamic diameter of

$2238.9 \mu \mathrm{m}$ (Fig. 5A). According to equation 1, these nanoparticles with a geometric diameter

224 of $50 \mathrm{~nm}$ and having a true density of $4.9 \mathrm{~g} / \mathrm{cm}^{3}$ should have an aerodynamic diameter of 
$225110 \mathrm{~nm}$ and deposit mainly on the filter stage of the impactor. The large deposition on

226 stage 1 is presumably due to the agglomeration of the nanoparticles in non-inhalable

227 large clusters. In fact, SPIONs had a high $\gamma_{s}{ }^{d}\left(147.5 \pm 42 \mathrm{~mJ} / \mathrm{m}^{2}\right.$, Table 1), favouring their

228 aggregation. The increase in PEG concentration in the formulation reduced $\gamma_{s}^{d}$ (Table 2),

229 decreasing the ability of the particles to aggregate. Besides preventing the particles from

230 aggregating, the PEG should also play a role in preventing nonspecific and irreversible

231 adsorption of foreign protein onto the particles, reducing opsonisation and particle

232 phagocytosis.

233 In order to reach the pulmonary alveoli, particles must have an aerodynamic equivalent

234 diameter $\left(d_{a}\right)$ in the 1-5 $\mu \mathrm{m}$ range [12]. The aerodynamic diameter is the diameter of a

235 sphere of unit density, which reaches the same velocity in the air stream as the particle

236 analysed, which can be nonspherical and have a different density [23, 24]. It is linked to

237 the volume-equivalent geometric diameter $\left(d_{g}\right)$ by the particle shape and density, as

238 described by the following equation [23, 24]:

$239 d_{a}=d_{g} \sqrt{\left(\frac{\rho_{p}}{\rho_{0} \cdot \chi}\right)}$

Eq. 1

240 Where $\rho_{0}$ is the standard particle density $(1 \mathrm{~g} / \mathrm{cc}), \chi$ is the particle shape factor that is 1 for

241 a sphere and $\rho_{p}$ is the apparent particle density. $\rho_{p}$ is equal to the mass of a particle

242 divided by its apparent volume, i.e. the total volume of the particle, excluding open pores,

243 but including closed pores [24], which can be less than the material density (true density)

244 if the particle is porous. Aerodynamic diameter decreases with increasing $\chi$. For an

245 irregular particle $\chi$ is always greater than 1 [24]. Also, in order to decrease $d_{a}$ of large or 
246 dense particles below $5 \mu \mathrm{m}$, several studies focused on enhancing the particle's porosity

247 to increase $\chi$ and decrease $\rho_{p}[11,15-17]$.

248 To increase the porosity of the particles, ammonium carbonate $\left(\mathrm{NH}_{4}\right)_{2} \mathrm{CO}_{3}$ was added to

249 the formulation. In fact, $\left(\mathrm{NH}_{4}\right)_{2} \mathrm{CO}_{3}$ is commonly used as a blowing agent, [12, 25] pore-

250 forming agent [12] or process enhancer [14, 15]. This compound decomposes at $60^{\circ} \mathrm{C}$

251 and produces gases during spray drying, thus it is able to create porous or hollow

252 particles. The addition of $\left(\mathrm{NH}_{4}\right)_{2} \mathrm{CO}_{3}$ to the PEG-SPIONs mixture did not change the

253 morphology of the particle aggregates (Figure 4A). It would appear that the partially

254 solidified PEG did not allow the formation of void cavities in the particles, which are

255 usually made by material solidification around the gas bubbles produced by the

$256\left(\mathrm{NH}_{4}\right)_{2} \mathrm{CO}_{3}$ decomposition on spray drying. However, the addition of ammonium

257 carbonate to the 50P-50H-50F formulation produced individual spherical and hollow

258 microparticles (Figure 4B). These microparticles had a median geometric diameter of 3

$259 \mu \mathrm{m}$ (Fig. 3) and SPIONs were observable on their surface, but appeared more entrapped

260 than when processing was undertaken in the absence of ammonium carbonate (Figure

261 2D). The deeper penetration of the SPIONs within the microparticles may allow for the

262 avoidance of SPIONs desorption from the surface of the microparticles due to the

263 mechanical stress produced during the dry powder inhalation. The large pores in these

264 microparticles should enhance their aerodynamic properties, and be favourable for

265 alveolar particle deposition.

266 The formulation of SPIONs-loaded microparticles made of PEG and HP $\beta C D$ with

$267\left(\mathrm{NH}_{4}\right)_{2} \mathrm{CO}_{3}\left(50 \mathrm{P}-50 \mathrm{H}-50 \mathrm{~F}-\mathrm{CO}_{3}\right)$ decreased the amount of particles collected on stage 1 of 268 the impactor from $49.8 \pm 9.0 \%$ (for SPIONs alone) to $35.1 \pm 6.4 \%$, and increased the 
amount collected on the other stages, with a gradual decrease in the amount deposited

270 with the decrease in the stage cut-off diameter (Fig. 5B). The application of a magnetic

271 field on stage 2 of the impactor changed the particle deposition profile. The percentage of

272 particles on stage 1,3 and 4 decreased and the percentage on stage 2 significantly

273 increased, 2.5-fold compared to the percentage obtained without magnetic field. Thus,

274 this type of particles was sensitive to the magnetic field; however, their aerodynamic

275 properties were not appropriate for targeting the deep lung area. The aerodynamic

276 properties of the $50 \mathrm{P}-50 \mathrm{H}-50 \mathrm{~F}-\mathrm{CO}_{3}$ microparticles showed a large measured MMAD

277 value $(10.2 \pm 2.0 \mu \mathrm{m})$ compared to the $d_{a}(3.66 \mu \mathrm{m})$ calculated with equation 1 using the

278 median volume-weighted geometric diameter $\mathrm{D}_{50}$, considering the particles to be

279 spherical and using the particles' true density (Table 2). This difference can be attributed

280 to the aggregation of the microparticles. Therefore, in order to reduce particle

281 aggregation, magnesium stearate $(\mathrm{MgST})$ was added to the formulation.

282 MgST is used in marketed DPI products $\left(\right.$ Seebri ${ }^{\circledR}$ Breezhaler $^{\circledR}$, Novartis; Foradil ${ }^{\circledR}$

283 Certihaler $^{\circledR}$, Novartis), and is commonly used to reduce the surface free energy [26] and

284 agglomeration of particles [27]. The carboxylate group of MgST may be coordinated to

285 the iron atom on the SPIONs surface via four different structures, as was previously

286 observed with oleic acid [28]. This would make the SPIONs surface less polar and less

287 adhesive and would change the SPIONs behaviour. However, it was found that the

288 dispersive part of the surface free energy $\left(\gamma_{s}^{d}\right)$ of the microparticles was not changed by

289 the addition of MgST. This component of the surface free energy of the Trojan

290 microparticle was already low due to the presence of PEG at the surface. The addition of

291 MgST to the formulations changed the particle morphology. SEM micrographs (Fig. 4C- 
292 D) showed individual microparticles with surfaces that appeared more porous compared 293 to particles formulated without MgST (Fig. 4B). This increase in porosity induced an 294 increase in the specific surface area, as measured by nitrogen adsorption (Table 2). Also, 295 rough or irregular particles may have very low effective van der Waals adhesion forces 296 [29], facilitating particle aerosolisation.

297 The addition of MgST into the formulation significantly decreased particle deposition on 298 stage 1 of the NGI, from $49.8 \pm 9.0 \%$ for nanoparticles alone to $1.8 \pm 0.3 \%$ of the 299 recovered dose for 50P-50H-50F-ST and increased the amount of particles recovered on 300 the other stages (Figure 5C). For the 50P-50H-50F-ST particles the main deposition 301 occurred on stages 2 and $3(22.9 \pm 3.4$ and $20.9 \pm 3.4 \%$, respectively), having a cut-off of 3024.46 and $2.82 \mu \mathrm{m}$, respectively, with a gradual decrease in the amount of powder 303 recovered on the other lower cut-off stages. These particles have a MMAD of $3.4 \pm 1 \mu \mathrm{m}$

304 which was higher than the aerodynamic diameter $(2.0 \mu \mathrm{m})$ calculated using equation 1 . In 305 the presence of magnets on stage 2, the amount of particles recovered on this stage 306 increased from $22.9 \pm 3.4$ to $32.6 \pm 4.9 \%$ and decreased on the following stages.

307 The addition of $\left(\mathrm{NH}_{4}\right)_{2} \mathrm{CO}_{3}$ and $\mathrm{MgST}$ to the formulation improved further the 308 aerodynamic properties of the Trojan particles, leading to the main deposition being 309 centred on stage $4(23.4 \pm 3.5 \%)$ which has a cut-off of $1.6 \mu \mathrm{m}$ (Figure $5 \mathrm{D})$. In the in vivo 310 situation, it would be expected that these particles would be spread out within the whole 311 lung. In the presence of a magnetic field on stage 2, the amount of particles deposited at 312 this stage significantly increased 4 -fold from $4.8 \pm 0.7 \%$ to $19.5 \pm 3.3 \%$. These Trojan 313 particles appeared more sensitive to the magnetic field than particles formulated without 
$314\left(\mathrm{NH}_{4}\right)_{2} \mathrm{CO}_{3}$ and $\mathrm{MgST}$ and the deposition on the NGI stage was significantly altered in

315 the presence of the magnet (Figure 5D).

316 These particles may be useful for treating localised lung disease, by targeting foci of

317 bacterial infection or tumour nodules. SPIONs released from the Trojan microparticles

318 should be eliminated from the lungs via mechanisms such as mucociliary clearance and

319 macrophage phagocytosis [30]. Even though it has already been used in inhalation in

320 humans, the inhalation of SPIONs may raise some toxicological concerns [31]. A

321 previous toxicological study [32] showed that intratracheally instilled $\mathrm{Fe}_{2} \mathrm{O}_{3}$

322 nanoparticles of $22 \mathrm{~nm}$ diameter could pass through the alveolar-capillary barrier into the

323 systemic circulation at a clearance rate of $3.06 \mathrm{mg} / \mathrm{day}$. The authors of this study

324 suggested that this absorption was probably due to macrophages clearance function

325 overloading, potentially resulting in lung cumulative toxicity of the nanoparticles.

326 PEG used in the formulations discussed here could be useful to prevent early stage

327 particle phagocytosis by alveolar macrophage, by forming a swelling/viscous crown

328 around the drug loaded microparticles to temporarily repulse macrophages [33, 34]. Thus,

329 the use of PEG in the current formulations could decrease the macrophage overloading

330 by slowing down the rate at which the particles are phagocytosed. After complete

331 solubilisation, PEG of $10 \mathrm{kDa}$ should diffuse from the lung into the blood circulation and

332 be eliminated by renal excretion, as its molecular weight is lower than $30 \mathrm{kDa}[35,36]$.

333 Other study performed on rats exposed to magnetite particles with a MMAD of $1.3 \mu \mathrm{m}$

334 for 13-week of inhalation showed no mortality, consistent changes in body weights, or

335 systemic toxicity. Elevations of neutrophils in bronchoalveolar lavage appeared to be the

336 most sensitive endpoint of the study [37]. Particle size appears to be determinant in 
337 SPIONs toxicity. For example, ultra small superparamagnetic particle of iron oxide 338 having a diameter of $5 \mathrm{~nm}$ were not toxic to human monocyte-macrophages in vitro and 339 did not activate them to produce pro-inflammatory cytokines or superoxide anions [38].

340 Nevertheless, we suggest that this approach of lung drug targeting by an external 341 magnetic field would be acceptable only in the case of a clear benefit such as in the case 342 of anticancer drug delivery [39] and if used at a low frequency. 


\section{$344 \quad 3-$ Conclusion}

345 This study demonstrates the feasibility of formulating SPIONs-loaded microparticles

346 which may be useful in the treatment of localised lung disease, such as foci of bacterial

347 infection or tumour nodules. The Trojan microparticles formulated were aerosolised

348 using a dry powder inhaler to produce inhalable particles. These particles were sensitive

349 enough to the magnetic field produced by a commercial magnet to induce a significant

350 change of their distribution on a cascade impactor. 


\section{4- Acknowledgement}

353 The authors acknowledge funding by a Strategic Research Cluster grant (07/SRC/B1154)

354 under the National Development Plan co-funded by EU Structural Funds and Science 355 Foundation Ireland.

356 
358 [1] L. Yildirimer, N.T.K. Thanh, M. Loizidou, A.M. Seifalian, Toxicological 359 considerations of clinically applicable nanoparticles, Nano Today, 6 (2011) 585-607.

360 [2] I. Chourpa, L. Douziech-Eyrolles, L. Ngaboni-Okassa, J.F. Fouquenet, S. Cohen361 Jonathan, M. Soucé, H. Marchais, P. Dubois, Molecular composition of iron oxide 362 nanoparticles, precursors for magnetic drug targeting, as characterized by confocal 363 Raman microspectroscopy, Analyst, 130 (2005) 1395-1403.

364 [3] E. Munnier, F. Tewes, S. Cohen-Jonathan, C. Linassier, L. Douziech-Eyrolles, H. 365 Marchais, M. Soucé, K. Hervé, P. Dubois, I. Chourpa, On the interaction of doxorubicin 366 with oleate ions: Fluorescence spectroscopy and liquid-liquid extraction study, Chemical and Pharmaceutical Bulletin, 55 (2007) 1006-1010.

[4] P. Pouponneau, J.C. Leroux, G. Soulez, L. Gaboury, S. Martel, Co-encapsulation of magnetic nanoparticles and doxorubicin into biodegradable microcarriers for deep tissue targeting by vascular MRI navigation, Biomaterials, 32 (2011) 3481-3486.

[5] C. Sapet, L. Le Gourrierec, U. Schillinger, O. Mykhaylyk, S. Augier, C. Plank, O. Zelphati, Magnetofection: Magnetically assisted \& targeted nucleic acids delivery, Drug Delivery Technology, 10 (2010) 24-29.

[6] A.L. Coates, Guiding Aerosol Deposition in the Lung, New England Journal of Medicine, 358 (2008) 304-305.

[7] J. Ally, B. Martin, M. Behrad Khamesee, W. Roa, A. Amirfazli, Magnetic targeting of aerosol particles for cancer therapy, Journal of Magnetism and Magnetic Materials, 293 (2005) 442-449.

379 [8] D. Upadhyay, S. Scalia, R. Vogel, N. Wheate, R.O. Salama, P.M. Young, D. Traini, 380 W. Chrzanowski, Magnetised thermo responsive lipid vehicles for targeted and controlled 381 lung drug delivery, Pharmaceutical Research, 29 (2012) 2456-2467.

382 [9] P. Dames, B. Gleich, A. Flemmer, K. Hajek, N. Seidl, F. Wiekhorst, D. Eberbeck, I. 383 Bittmann, C. Bergemann, T. Weyh, L. Trahms, J. Rosenecker, C. Rudolph, Targeted 384 delivery of magnetic aerosol droplets to the lung, Nature Nanotechnology, 2 (2007) 495385499.

386 [10] N. Laurent, C. Sapet, L. Le Gourrierec, E. Bertosio, O. Zelphati, Nucleic acid

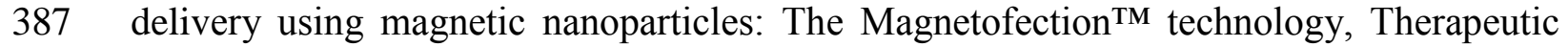
388 Delivery, 2 (2011) 471-482.

389 [11] N. Tsapis, D. Bennett, B. Jackson, D.A. Weitz, D.A. Edwards, Trojan particles: 390 Large porous carriers of nanoparticles for drug delivery, Proceedings of the National 391 Academy of Sciences of the United States of America, 99 (2002) 12001-12005. 
395 [13] D.E. Geller, J. Weers, S. Heuerding, Development of an inhaled dry-powder 396 formulation of tobramycin using PulmoSphere technology, J Aerosol Med Pulm Drug 397 Deliv, 24 (2011) 175-182. free nanoporous microparticles (NPMPs) of bendroflumethiazide, European Journal of Pharmaceutics and Biopharmaceutics, 69 (2008) 1182-1186.

401 [15] L.M. Nolan, L. Tajber, B.F. McDonald, A.S. Barham, O.I. Corrigan, A.M. Healy, 402 Excipient-free nanoporous microparticles of budesonide for pulmonary delivery, European Journal of Pharmaceutical Sciences, 37 (2009) 593-602.

[16] L.M. Nolan, J. Li, L. Tajber, O.I. Corrigan, A.M. Healy, Particle engineering of materials for oral inhalation by dry powder inhalers. II - Sodium cromoglicate, International Journal of Pharmaceutics, 405 (2011) 36-46.

407 [17] F. Tewes, K.J. Paluch, L. Tajber, K. Gulati, D. Kalantri, C. Ehrhardt, A.M. Healy, 408 Steroid/mucokinetic hybrid nanoporous microparticles for pulmonary drug delivery, 409 European Journal of Pharmaceutics and Biopharmaceutics, (2013).

410 [18] F. Tewes, O.L. Gobbo, M.I. Amaro, L. Tajber, O.I. Corrigan, C. Ehrhardt, A.M. 411 Healy, Evaluation of HP $\beta C D-P E G$ microparticles for salmon calcitonin administration 412 via pulmonary delivery, Molecular Pharmaceutics, 8 (2011) 1887-1898.

413 [19] F. Tewes, L. Tajber, O.I. Corrigan, C. Ehrhardt, A.M. Healy, Development and 414 characterisation of soluble polymeric particles for pulmonary peptide delivery, European 415 Journal of Pharmaceutical Sciences, 41 (2010) 337-352.

416 [20] J. Schultz, L. Lavielle, C. Martin, The role of the interface in carbon-fiber epoxy 417 composites, J Adhes, 23 (1987) 45-60.

418 [21] G.A. Sotiriou, E. Diaz, M.S. Long, J. Godleski, J. Brain, S.E. Pratsinis, P. 419 Demokritou, A novel platform for pulmonary and cardiovascular toxicological 420 characterization of inhaled engineered nanomaterials, Nanotoxicology, 6 (2012) 680-690.

421 [22] R. Vehring, Pharmaceutical particle engineering via spray drying, Pharmaceutical 422 Research, 25 (2008) 999-1022.

423 [23] B. Shekunov, P. Chattopadhyay, H.Y. Tong, A.L. Chow, Particle Size Analysis in 424 Pharmaceutics: Principles, Methods and Applications, Pharmaceutical Research, 24 425 (2007) 203-227. 

Morphology and Density Characterization by Combined Mobility and Aerodynamic 428 Diameter Measurements. Part 1: Theory, Aerosol Science and Technology, 38 (2004) 429 1185-1205.

430 [25] D. Traini, P. Young, P. Rogueda, R. Price, In Vitro Investigation of Drug 431 Particulates Interactions and Aerosol Performance of Pressurised Metered Dose Inhalers, 432 Pharmaceutical Research, 24 (2007) 125-135.

433 [26] V. Swaminathan, J. Cobb, I. Saracovan, Measurement of the surface energy of 434 lubricated pharmaceutical powders by inverse gas chromatography, International Journal 435 of Pharmaceutics, 312 (2006) 158-165.

436 [27] Q.T. Zhou, L. Qu, I. Larson, P.J. Stewart, D.A.V. Morton, Improving aerosolization of drug powders by reducing powder intrinsic cohesion via a mechanical dry coating approach, International Journal of Pharmaceutics, 394 (2010) 50-59.

[28] L.N. Okassa, H. Marchais, L. Douziech-Eyrolles, K. Hervé, S. Cohen-Jonathan, E. Munnier, M. Soucé, C. Linassier, P. Dubois, I. Chourpa, Optimization of iron oxide nanoparticles encapsulation within poly(d,l-lactide-co-glycolide) sub-micron particles, 442 European Journal of Pharmaceutics and Biopharmaceutics, 67 (2007) 31-38.

443 [29] O.R. Walton, Review of Adhesion Fundamentals for Micron-Scale Particles, KONA 444 Powder and Particle Journal, 26 (2008) 129-141.

445 [30] D.B. Buxton, Nanomedicine for the management of lung and blood diseases, 446 Nanomedicine, 4 (2009) 331-339.

447 [31] W. Moller, K. HauSZinger, L. Ziegler-Heitbrock, J. Heyder, Mucociliary and long448 term particle clearance in airways of patients with immotile cilia, Respiratory Research, 7 449 (2006) 10.

450 [32] M.T. Zhu, W.Y. Feng, Y. Wang, B. Wang, M. Wang, H. Ouyang, Y.L. Zhao, Z.F. 451 Chai, Particokinetics and extrapulmonary translocation of intratracheally instilled ferric 452 oxide nanoparticles in rats and the potential health risk assessment, Toxicol Sci., 107 453 (2009) 342-351. Epub 2008 Nov 2020.

454 [33] I.M. El-Sherbiny, H.D. Smyth, Controlled release pulmonary administration of 455 curcumin using swellable biocompatible microparticles, Mol Pharm, 9 (2012) 269-280.

456 [34] I.M. El-Sherbiny, S. McGill, H.D. Smyth, Swellable microparticles as carriers for 457 sustained pulmonary drug delivery, J Pharm Sci, 99 (2010) 2343-2356.

458 [35] C.J. Fee, Size comparison between proteins PEGylated with branched and linear 459 poly(ethylene glycol) molecules, Biotechnology and Bioengineering, 98 (2007) 725-731. 
460 [36] J.M. Harris, R.B. Chess, Effect of pegylation on pharmaceuticals, Nat Rev Drug 461 Discov, 2 (2003) 214-221.

462 [37] J. Pauluhn, Subchronic inhalation toxicity of iron oxide (magnetite, Fe3O4) in rats: 463 pulmonary toxicity is determined by the particle kinetics typical of poorly soluble 464 particles, Journal of Applied Toxicology, 32 (2012) 488-504.

465 [38] K. Müller, J.N. Skepper, M. Posfai, R. Trivedi, S. Howarth, C. Corot, E. Lancelot, 466 P.W. Thompson, A.P. Brown, J.H. Gillard, Effect of ultrasmall superparamagnetic iron 467 oxide nanoparticles (Ferumoxtran-10) on human monocyte-macrophages in vitro, 468 Biomaterials, 28 (2007) 1629-1642.

469 [39] C. Rudolph, B. Gleich, A.W. Flemmer, Magnetic aerosol targeting of nanoparticles 470 to cancer: nanomagnetosols, Methods in molecular biology (Clifton, N.J.), 624 (2010) $471 \quad 267-280$. 


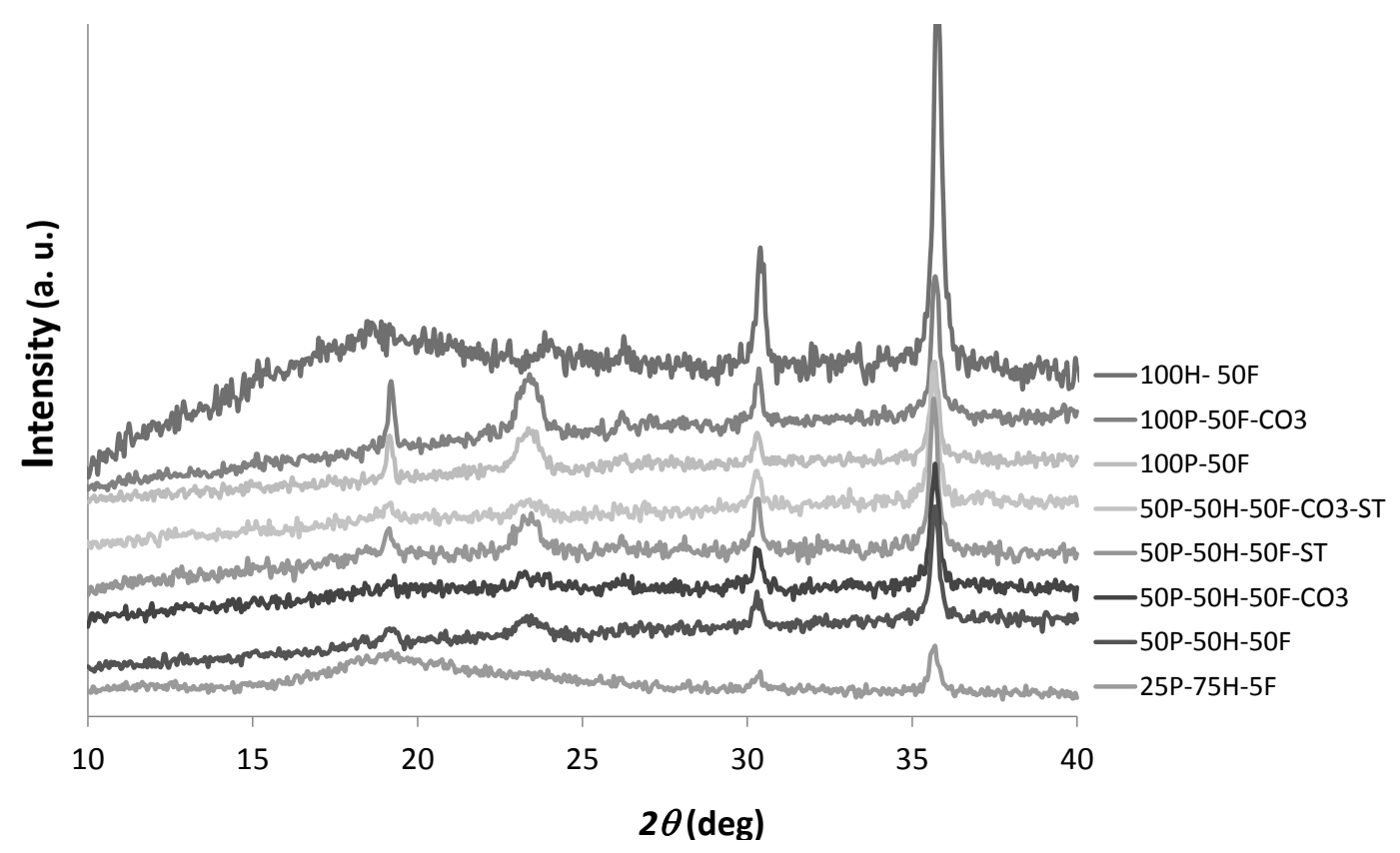

$474 \quad$ Figure 1: Powder X-ray diffractograms of hybrid SPION loaded microparticles 

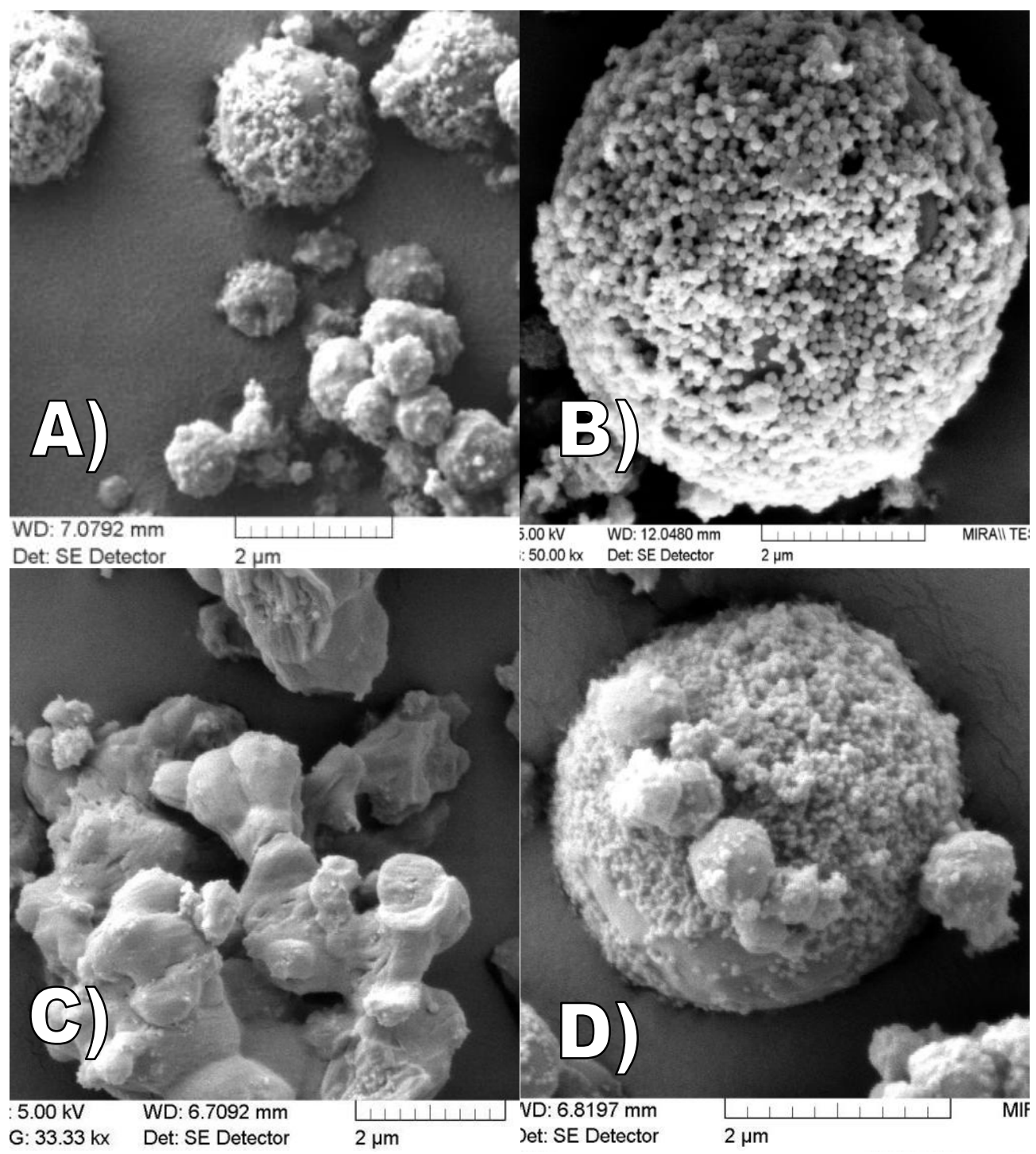

489 Figure 2: SEM micrographs of trojan hybrid SPION loaded microparticles: A) 25P-75H-5F' B)

$490 \quad 25 \mathrm{P}-75 \mathrm{H}-30 \mathrm{~F}^{\prime}$ C) 100P-50F, D) 50P-50H-50F. 

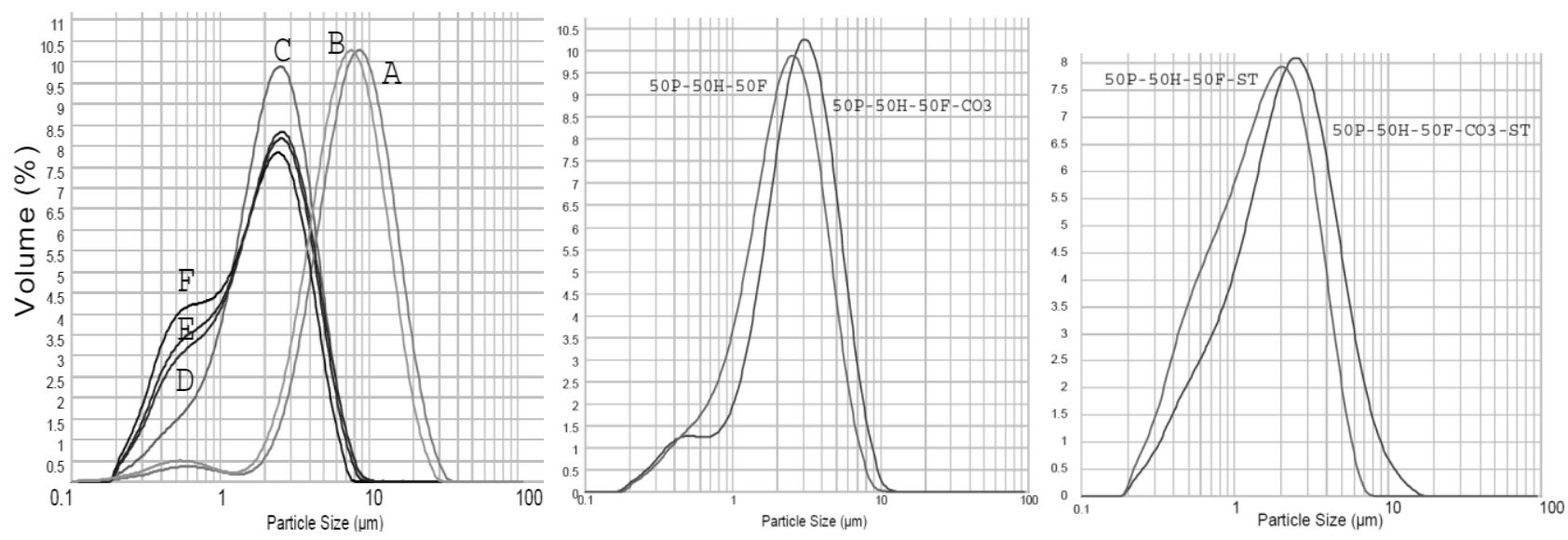

493 Figure 3: Geometric particles size distribution of hybrid SPION loaded microparticles. A: 100P-

494 50F; B: 100P-50F-CO3; C: 50P-50H-50F; D: 25P-75H-30F; E: 25P-75H-5F, F: 100HP-50F. 


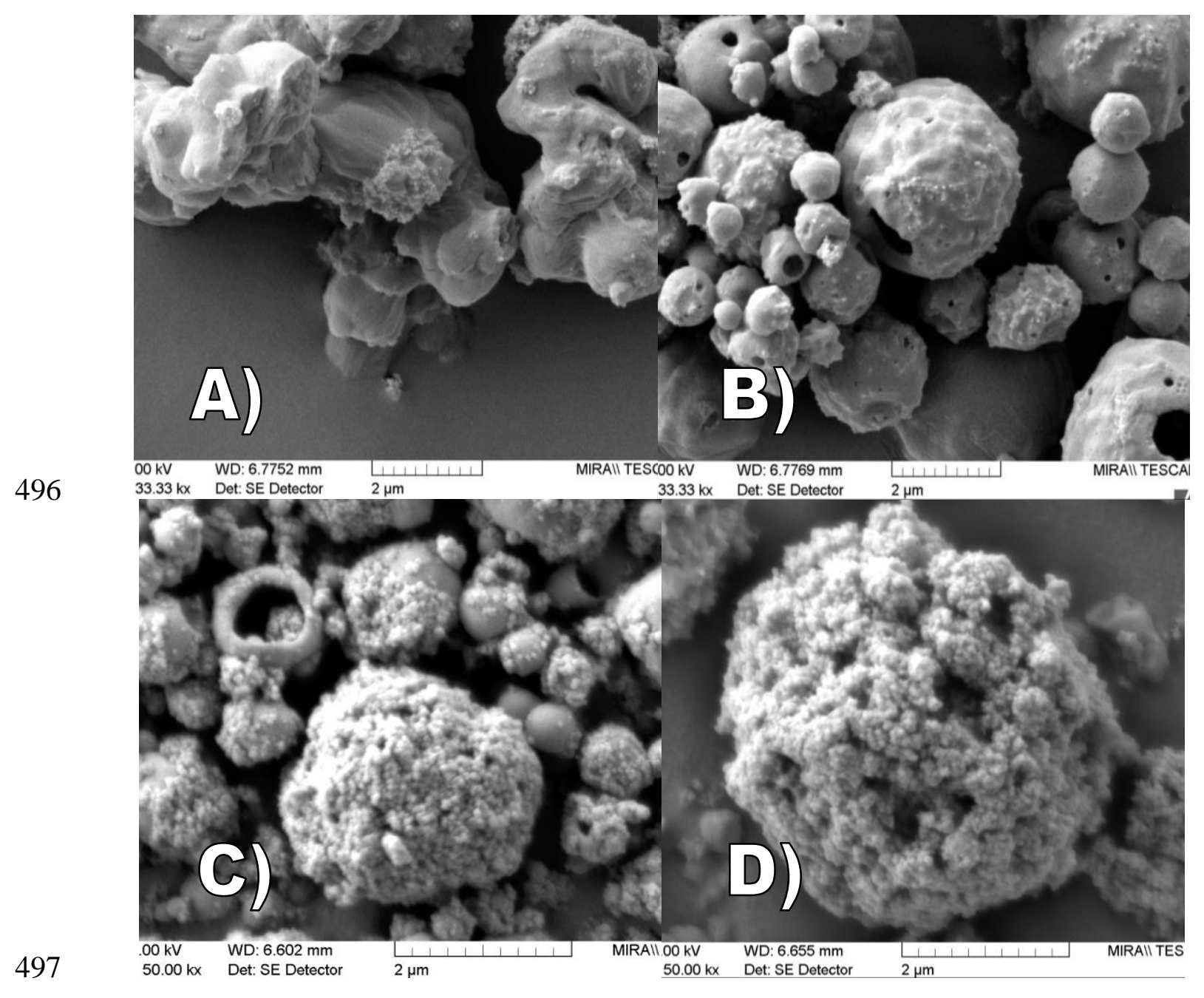

498 Figure 4: SEM micrographs of hybrid SPION loaded microparticles formulated with $\left.\left(\mathrm{NH}_{4}\right)_{2} \mathbf{C O}_{3}: \mathrm{A}\right)$ 499 100P-50F-CO $\mathbf{C O}_{3}$, B) 50P-50H-50F-CO . $_{3}$ SEM micrographs of hybrid SPION loaded microparticles 500 formulated with Mg-ST: C) 50P-50H-50F-ST, D) 50P-50H-50F-ST-CO 

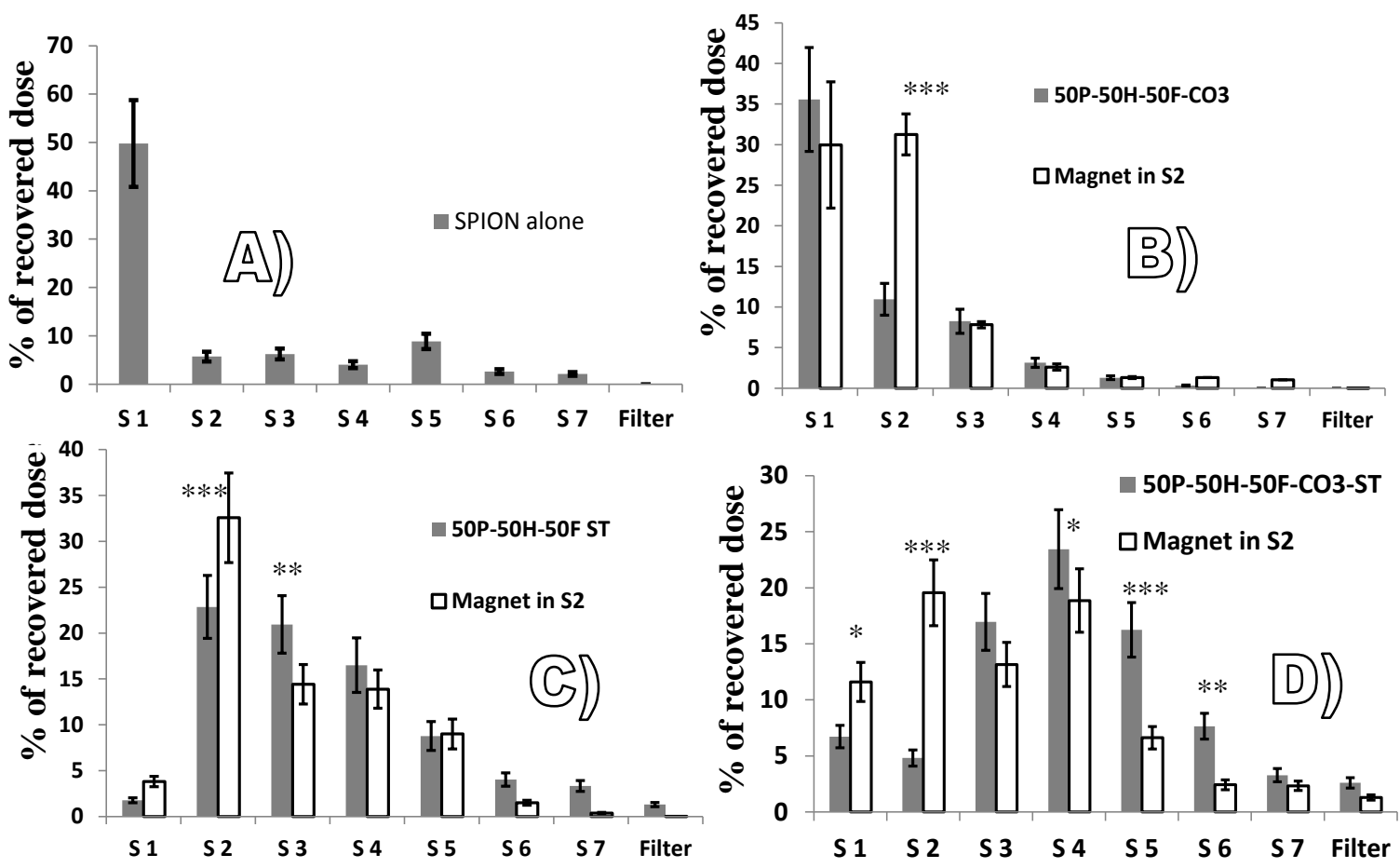

Figure 5: Mass percentage of the recovered total dose of the trojan microparticles, i.e. the total amount of powder collected from the device, capsule and impactor recovered on each NGI stage, with and without a magnetic field applied on stage 2 . Two-way ANOVA, $* P<0.05$; ** $\mathrm{P}<0.01 ; * * * \mathrm{P}<0.001$. 
510

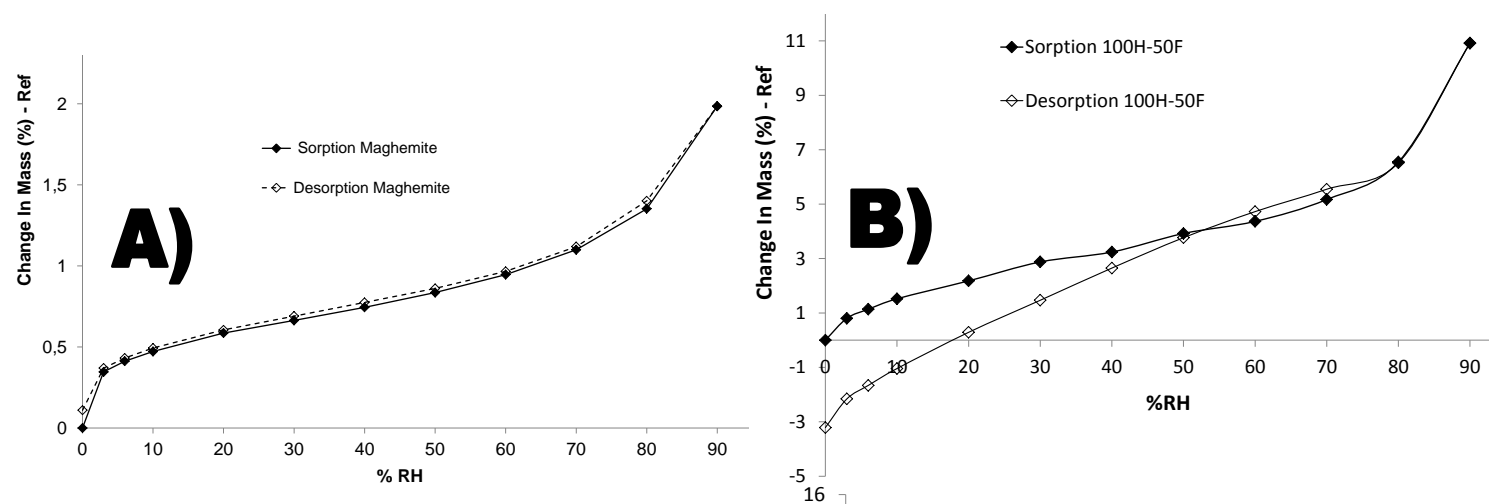

511
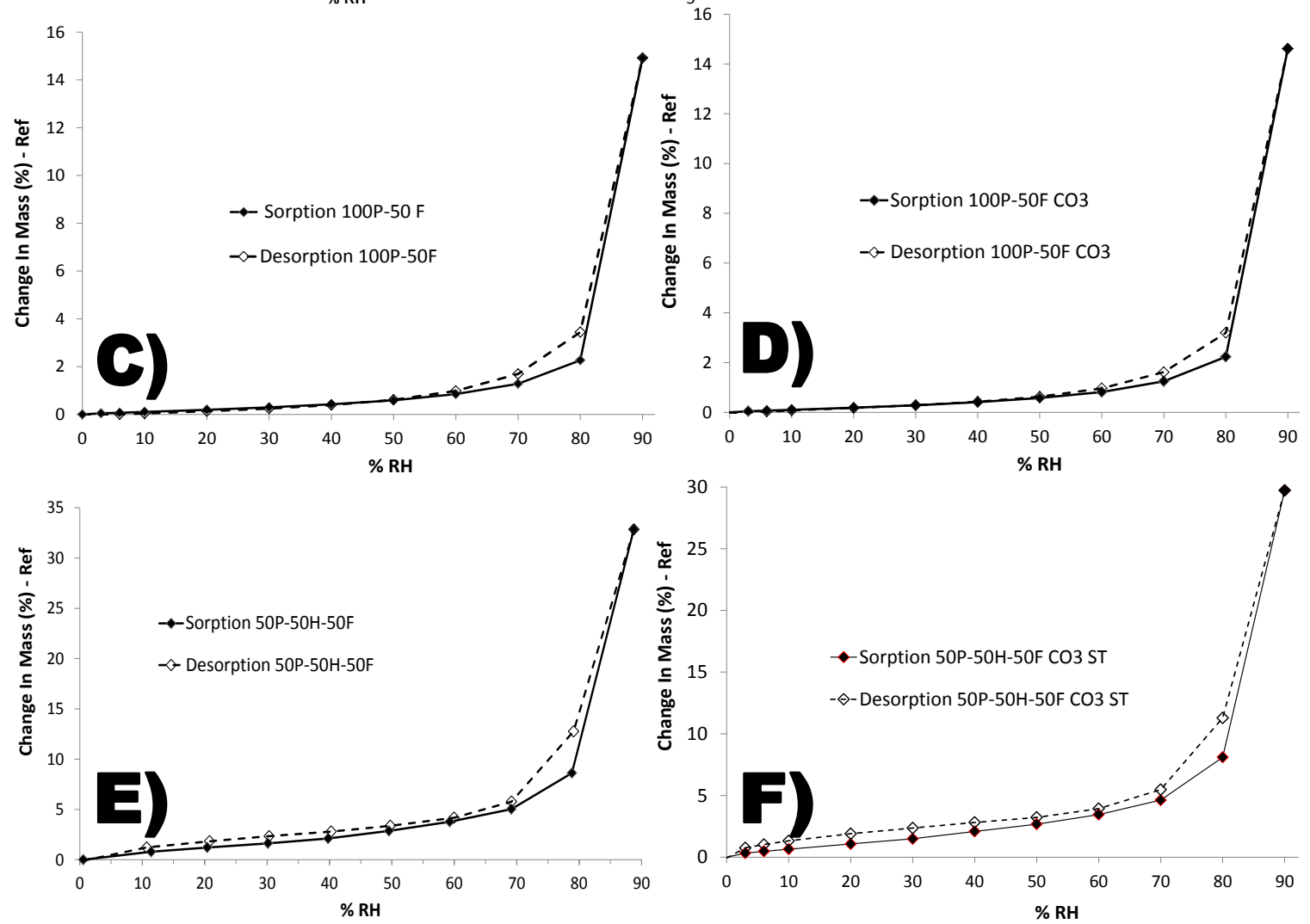

513 Figure 5: Water sorption isotherms. A) SPION alone, B) 100HP-50F, C) 100P-50F, D) 100P-50F514 CO3, E) 50P-50H-50F, F) 50P-50H-50F-CO3-ST

515 